\title{
Sexual dysfunction in Nigerian stroke survivors
}

\author{
Akinpelu $\mathrm{AO}^{1},{ }^{*}$ Osose $\mathrm{AA}^{2}$, Odole $\mathrm{AC}^{1}$, Odunaiya $\mathrm{NA}^{1}$
}

1. Department of Physiotherapy, College of Medicine, University of Ibadan, Ibadan, Oyo State, Nigeria. 2. Department of Physiotherapy, University College Hospital, Ibadan, Oyo State, Nigeria.

\begin{abstract}
Background: Over three-quarters of stroke survivors experience disruption of sexual functioning. Studies reporting poststroke sexual function of Nigerian patients are few.

Objectives: This survey reports sexual dysfunction in Nigerian stroke survivors, and determines the influence of sociodemographic, clinical and psychological factors on the dysfunction.

Methods: Participants were 77 stroke survivors (60 males; 17 females) recruited consecutively from a teaching hospital. Participants completed the Beck Depression Inventory, Stroke Specific Quality of Life Scale and post-stroke sexual function questionnaire. Participants' motor ability was rated on the Modified Motor Assessment Scale. Data were analysed using Chi square test and Mann-Whitney $U$ test (alpha level set at 0.05).

Results: Participants were aged 55.2 \pm 10.8 (28-79) years. Most (94.8\%) participants reported a dysfunction in sexual function. Decline in libido and coital frequency were reported by $>70 \%$ and in erection, ejaculation and orgasm by $>60 \%$ of participants. Participants' with erectile dysfunction were significantly older than those without $(U=267.0 ; p=0.02)$. Depression, quality of life, willingness to have sex, general attitude to sex and ability to express sexual feelings had significant influence on sexual dysfunction reported by participants $(\mathrm{p}<0.05)$.

Conclusion: Our findings suggest that sexual dysfunction is common among Nigerian stroke survivors and it is mostly associated with psychological factors.

Keywords: Stroke-Survivors, Sexual dysfunction, Psychological factors, Quality of life

African Health Sciences 2013; 13(3): 639 - 645 http:/ / dx.doi.org/10.4314/ahs.v13i3.17
\end{abstract}

\section{Introduction}

Stroke is a major cause of long-term disability worldwide, as it results in considerable impairment of sensory, motor, mental, perceptual and language functions ${ }^{1}$. It is a leading cause of morbidity and mortality in adults in the productive ages ${ }^{2}$. Stroke was believed to be rare in the Black Africans five decades ago $^{3}$, but is known to be common in developing countries such as Nigeria as in the Western world ${ }^{4}$.

Sexuality is an integral part of normal life in men and women of all ages. A marked decline in sexuality has been reported after stroke. It has been reported that as many as three-quarters of stroke survivors experience disruption of sexual functioning. According to Buzzelli et $\mathrm{al}^{5}$ and Korpelainen et $\mathrm{al}^{6}$, post-stroke decline in sexual function was predominantly due to psychological rather than physiological causes. However, other authors have

\begin{tabular}{|l|}
\hline${ }^{*}$ Corresponding author: \\
Osose A Akinpelu \\
Department of Physiotherapy \\
University College Hospital \\
Ibadan, Oyo State \\
Nigeria. \\
Email: adebimpe.osose@gmail.com \\
\hline
\end{tabular}

African Health Sciences Vol 13 Issue 3 September 2013 identified the causes to include anatomical lesion in the brain, pre-morbid medical conditions (diabetes, hypertension, cardiac disease), and several interpersonal factors ${ }^{5,7}$. The most commonly reported post-stroke sexual problems include decline in libido and coital frequency, reduced vaginal lubrication and orgasmic ability in women, and poor or absent erection and ejaculation in men as well as decreased enjoyment and satisfaction with sexual life. In cultures where it is more or less a taboo to discuss sexuality publicly, discussing sexuality with individuals with neurologic disabilities is difficult and thus makes its rehabilitation difficult ${ }^{8}$. This is probably the reason for the negligent attitude shown by professionals towards the effect of stroke on sexuality and the sexual health of stroke survivors?.

Studies reporting sexual dysfunction among stroke survivors in Nigeria are not common. The only study from Nigeria reported decline in sexual function in a small sample of male stroke survivors with hemiparesis, attending a hospital in Northern Nigeria ${ }^{10}$.

The aims of the present study were to survey sexual dysfunction among stroke survivors attending a hospital in Southwestern Nigeria, and to determine 
the influence of socio-demographic, clinical and psychological factors on the dysfunction.

\section{Methods}

The study protocol was approved by the University of Ibadan and University College Hospital, Ibadan Research Ethics Committee. Participants were 77 stroke survivors attending physiotherapy out-patient department of the University College Hospital, Ibadan, Nigeria. They were recruited consecutively over a period of 9 months (October, 2008 to July, 2009). Only male and female Nigerians who have had stroke for at least three months, who were married and/or were living with their spouse(s) and who gave informed consent participated in this study.

Participant's socio-demographic and clinical information (age, gender, duration of stroke, presence and side of hemiparesis/hemiplegia) were collected through interview and from participants' hospital files. Their motor ability was rated on the Modified Motor Assessment Scale ${ }^{11}$ by one of the authors. Participants then completed 3 questionnaires which were the Stroke Specific Quality of Life Scale $(\mathrm{SS}-\mathrm{QOL})^{12}$, the Beck Depression Inventory ${ }^{13}$ and a questionnaire on sexual dysfunction in stroke survivors adapted from a previous study ${ }^{6}$. The order of administration of the questionnaire was randomized using fish bowling method. The questionnaire on post-stroke sexual dysfunction included seven sexual functions (libido, coital frequency, erection, ejaculation vaginal lubrication, orgasm and satisfaction with sexual life). Two sexual functions (erection, ejaculation) were specific to males and one (vaginal lubrication) was specific to females. Participants were asked to rate each sexual function based on their post-stroke sexual state relative to their pre-stroke sexual state on a 4 or 5 point likert scale as follows: libido: (1) increased, (2) no change, (3) diminished, (4) markedly diminished, (5) none; coital frequency: (1) more than once a week, (2) once a week, (3) once or twice a month, (4) less than once a month, (5) none; erection, ejaculation, vaginal lubrication, and orgasm: (1) normal, (2) slightly diminished, (3) markedly diminished, (4) none; satisfaction with sexual life: (1) very satisfied, (2) moderately satisfied, (3) moderately dissatisfied, (4) completely dissatisfied. The questionnaire also included five psychological factors which were: General attitude towards sexuality: (1) extremely important, (2) fairly important, (3) unimportant; Fear of impotence: (1) no, (2) yes; Fear of another stroke: (1) no, (2) yes; Ability to discuss sexuality with the spouse: (1) yes, with ease, (2) yes, with trouble, (3) no; Unwillingness to participate in sexual activity: (1) no, (2) yes.

Sexual dysfunction was defined in terms of response options as follows: Libido dysfunctiondiminished, markedly diminished and no libido; coital frequency dysfunction- once or twice a month, less than once a month and no coitus; penile erection, ejaculation, vaginal lubrication orgasm dysfunctionslightly diminished, markedly diminished and none; dissatisfaction with sexual life - moderately dissatisfied and completely dissatisfied. Prior to data collection, each of the 3 questionnaires was translated into Yoruba (the indigenous language of the southwestern Nigeria) by two language experts, who later produced a consensus translation which was taken through the process of back translation and review by an expert panel ${ }^{14}$. This ensured the participation of stroke-survivors who were not literate in English

Data were summarized using frequency, percentage, median, mean and standard deviation. Inferential statistics of Chi Square test and MannWhitney $\mathrm{U}$ test were used to analyze data. The alpha level was set at 0.05 .

\section{Results}

A total of seventy seven stroke survivors comprising 60 males $(77.9 \%)$ and 17 females $(22.1 \%)$ participated in the study. Their age ranged from 28 to 79 years with a mean of $55.2+10.8$ years. The mean age for the males was $57.0 \pm 10.0$ (38 to 79 ) years and that of the females was $48.4 \pm 10.2$ (28 to 65 ) years. Thirtythree $(43.4 \%)$ had right hemiparesis and $43(56.6 \%)$ had left hemiparesis. Participants have had stroke for 3-84 months (median of stroke duration was 13.5 months. Participants had a mean depression score of $13.1 \pm 8.3$ (out of a maximum obtainable score of 63) and a mean quality of life score of $181.0 \pm 30.5$ (out of a maximum obtainable score of 245). Sixty three $(81.9 \%)$ of the participants regarded sex as important and $52(67.5 \%)$ could express sexual feelings to their spouses and $48(62 \%)$ expressed unwillingness to have sex. Thirty-nine participants $(50.6 \%)$ had fear of another stroke episode and 31 males $(60 \%)$ had fear of impotence.

Seventy-three $(94.8 \%)$ reported a dysfunction in one or more of the 7 sexual activities (libido, coital frequency, vaginal lubrication, erection, ejaculation, orgasm, satisfaction with sexual life) considered in this study (table 1). More than $70 \%$ of participants reported dysfunctions in libido and coital frequency and over 60\% reported dysfunction in 
erection, ejaculation and orgasm. The least frequently reported sexual dysfunction was dissatisfaction with sexual life which was expressed by 30 (39\%) of participants (table 1). Table 2 shows the frequency distribution of participants with or without dysfunction by gender, clinical and psychological variables.

Table 1: Frequency distribution of participants with and without Sexual dysfunction post stroke

\begin{tabular}{|c|c|c|c|c|c|}
\hline \multirow[t]{2}{*}{ Variables } & \multirow[t]{2}{*}{ n } & \multicolumn{2}{|c|}{$\begin{array}{l}\text { Without } \\
\text { dysfunction }\end{array}$} & \multicolumn{2}{|c|}{ With dysfunction } \\
\hline & & $\mathbf{F}$ & $\%$ & $\mathbf{F}$ & $\%$ \\
\hline Libido & 77 & 23 & 29.9 & 54 & 70.1 \\
\hline Coital frequency & 77 & 18 & 23.3 & 59 & 76.7 \\
\hline Erection & 60 & 23 & 38.3 & 37 & 61.7 \\
\hline Ejaculation & 60 & 22 & 36.7 & 38 & 63.3 \\
\hline Vaginal lubrication & 17 & 9 & 52.9 & 8 & 47.1 \\
\hline Orgasm & 77 & 28 & 36.4 & 49 & 63.6 \\
\hline Sexual satisfaction & 77 & 47 & 61.0 & 30 & 39.0 \\
\hline $\begin{array}{l}\text { Any sexual } \\
\text { dysfunction }\end{array}$ & 77 & 4 & 5.2 & 73 & 94.8 \\
\hline
\end{tabular}

Table 2: Frequency distribution of participants with or without sexual dysfunction by Gender, Clinical and Psychological variables

\begin{tabular}{lcccccccccccccc}
\hline Variable & LB & & CF & & ER & & EJ & & VL & & OR & & SS & \\
& ND & D & ND & D & ND & D & ND & D & ND & D & ND & D & ND & D \\
\hline Gender & 37 & 23 & 26 & 34 & 23 & 37 & 22 & 38 & - & - & 22 & 38 & 37 & 23 \\
$\begin{array}{l}\text { Male } \\
\text { Female }\end{array}$ & 10 & 7 & 9 & 8 & - & - & - & - & 9 & 8 & 6 & 11 & 10 & 7 \\
$\begin{array}{l}\text { Side of Hemiparesis } \\
\text { Right }\end{array}$ & 18 & 15 & 13 & 20 & 9 & 16 & 8 & 17 & 5 & 3 & 11 & 22 & 18 & 15 \\
Left & 29 & 14 & 22 & 21 & 14 & 21 & 14 & 21 & 4 & 4 & 17 & 26 & 29 & 14 \\
Attitude to Sex & & & & & & & & & & & & & & \\
Important & 42 & 21 & 33 & 30 & 20 & 29 & 21 & 28 & 8 & 6 & 27 & 36 & 42 & 21 \\
unimportant & 5 & 9 & 2 & 12 & 3 & 8 & 1 & 10 & 1 & 2 & 1 & 13 & 5 & 9 \\
Fear of Impotence & & & & & & & & & & & & & & \\
No & 24 & 14 & 17 & 21 & 16 & 22 & 13 & 25 & - & - & 15 & 23 & 24 & 14 \\
yes & 13 & 9 & 9 & 13 & 7 & 15 & 9 & 13 & - & - & 7 & 15 & 13 & 9 \\
Fear of another stroke & & & & & & & & & & & & & & \\
No & 25 & 13 & 17 & 21 & 14 & 19 & 13 & 20 & 3 & 2 & 16 & 22 & 25 & 13 \\
yes & 22 & 17 & 18 & 21 & 9 & 18 & 9 & 18 & 6 & 6 & 12 & 27 & 22 & 17 \\
Express sexual feelings & & & & & & & & & & & & & & \\
Yes & 35 & 17 & 31 & 21 & 18 & 22 & 19 & 21 & 6 & 6 & 22 & 30 & 35 & 17 \\
No & 12 & 13 & 4 & 21 & 5 & 15 & 3 & 17 & 3 & 2 & 6 & 19 & 12 & 13 \\
Unwilling to have sex & & & & & & & & & & & & & & \\
Yes & 16 & 13 & 11 & 18 & 20 & 19 & 21 & 18 & 5 & 4 & 7 & 22 & 16 & 13 \\
No & 31 & 17 & 24 & 24 & 3 & 18 & 1 & 20 & 4 & 4 & 21 & 27 & 31 & 17 \\
\hline
\end{tabular}

LB - Libido CF- Coital Frequency ER- Erection EJ - Ejaculation VL- Vaginal Lubrication ND- No Dysfunction D- Dysfunction 
Table 3: Association between sexual dysfunctions and gender, clinical, psychological variables

\begin{tabular}{|c|c|c|c|c|c|c|c|c|c|c|c|c|}
\hline \multirow[t]{2}{*}{ Variable } & LB & CF & \multicolumn{2}{|l|}{ ER } & \multicolumn{2}{|l|}{ EJ } & \multicolumn{2}{|l|}{ VL } & \multicolumn{2}{|l|}{ OR } & \multicolumn{2}{|l|}{ ss } \\
\hline & $\chi^{2} \quad P$-value & $\chi^{2} \quad P$-value & $x^{2}$ & P-value & $\chi^{2}$ & P-value & $x^{2}$ & P-value & $x^{2}$ & P-value & $x^{2}$ & P-value \\
\hline \multicolumn{13}{|l|}{ Gender } \\
\hline Male & \multirow[t]{2}{*}{0.3060 .580} & \multirow[t]{2}{*}{0.4930 .483} & - & - & - & - & - & - & \multirow{2}{*}{\multicolumn{2}{|c|}{0.0110 .917}} & \multicolumn{2}{|c|}{0.0450 .832} \\
\hline \multicolumn{9}{|l|}{ Female } & & & & \\
\hline \multicolumn{13}{|c|}{ Side of Hemiparesis } \\
\hline Right & \multirow[t]{2}{*}{0.0000 .995} & \multirow[t]{2}{*}{1.0410 .308} & \multirow{2}{*}{\multicolumn{2}{|c|}{0.0990 .753}} & \multirow{2}{*}{\multicolumn{2}{|c|}{0.4020 .526}} & \multirow{2}{*}{\multicolumn{2}{|c|}{0.2540 .614}} & \multirow{2}{*}{\multicolumn{2}{|c|}{0.3090 .579}} & \multirow{2}{*}{\multicolumn{2}{|c|}{1.3160 .251}} \\
\hline Left & & & & & & & & & & & & \\
\hline Attitude to & & & & & & & & & & & & \\
\hline Important & \multirow[t]{3}{*}{0.5820 .445} & \multirow[t]{3}{*}{$6.7050 .010^{*}$} & \multirow{3}{*}{\multicolumn{2}{|c|}{0.6970 .404}} & \multirow{3}{*}{\multicolumn{2}{|c|}{$4.4110 .036^{*}$}} & \multirow{3}{*}{\multicolumn{2}{|c|}{0.5620 .453}} & \multirow{3}{*}{\multicolumn{2}{|c|}{$6.3140 .012^{*}$}} & \multirow{3}{*}{\multicolumn{2}{|c|}{$4.6150 .032^{*}$}} \\
\hline unimporta & & & & & & & & & & & & \\
\hline Fear of Imp & & & & & & & & & & & & \\
\hline No & \multirow[t]{2}{*}{0.2080 .649} & 0.0830 .773 & 0.62 & 240.430 & 0.26 & 690.604 & - & - & 0.35 & 20.553 & 0.097 & $7 \quad 0.755$ \\
\hline yes & & & & & & & & & & & & \\
\hline Fear of ano & & & & & & & & & & & & \\
\hline No & 1.7410 .187 & 0.0160 .901 & 0.51 & 190.471 & 0.23 & 350.628 & 0.14 & 120.707 & & 91.301 & 0.712 & 20.399 \\
\hline yes & & & & & & & & & & & & \\
\hline Expressser & & & & & & & & & & & & \\
\hline Yes & 3.4000 .065 & $12.9540 .001^{*}$ & 2.25 & 660.133 & 6.06 & $650.014^{*}$ & 0.14 & 120.707 & 2.44 & 150.118 & 2.647 & $\begin{array}{ll}7 & 0.104\end{array}$ \\
\hline No & & & & & & & & & & & & \\
\hline Unwillingt & & & & & & & & & & & & \\
\hline Yes & $5.7400 .017^{*}$ & 1.0620 .303 & 7.90 & $40.005^{*}$ & 14.1 & $1620.001^{*}$ & 0.05 & 20.819 & 3.00 & 50.083 & 0.673 & 30.412 \\
\hline No & & & & & & & & & & & & \\
\hline
\end{tabular}

LB - Libido CF- Coital Frequency EF- Erection $\quad$ EJ - Ejaculation VL- Vaginal Lubrication OR- Orgasm SS- Satisfaction with Sexual Life * statistically significant at $\mathrm{p}<0.05 \mathrm{Chi}^{2}=$ chi square value

Table 4: Mean values of selected variables of participants With and Without Sexual dysfunction

\begin{tabular}{|c|c|c|c|c|c|c|c|c|c|c|c|c|c|c|}
\hline \multirow[t]{2}{*}{ Variable } & \multicolumn{2}{|l|}{ LB } & \multicolumn{2}{|l|}{$\mathrm{CF}$} & \multicolumn{2}{|l|}{ ER } & \multicolumn{2}{|l|}{$\mathrm{EJ}$} & \multicolumn{2}{|l|}{ VL } & \multicolumn{2}{|l|}{ OR } & \multicolumn{2}{|l|}{ SS } \\
\hline & ND & D & ND & $\mathrm{D}$ & ND & D & ND & D & ND & D & ND & D & ND & D \\
\hline \multicolumn{15}{|l|}{ Age (years) } \\
\hline $\mathrm{N}^{\circ}$ & 53.8 & 55.6 & 54.5 & 55.5 & 53.1 & 59.4 & 53.4 & 59.1 & 45.9 & 51.3 & 54.8 & 54.6 & 55.3 & 55.9 \\
\hline SD & 8.74 & 11.37 & 10.54 & 10.80 & 9.87 & 9.94 & 9.67 & 9.77 & 11.60 & 8.17 & 10.60 & 10.26 & 10.74 & 11.30 \\
\hline \multicolumn{15}{|c|}{$\begin{array}{l}\text { Stroke duration } \\
\text { (months) }\end{array}$} \\
\hline $\mathrm{N}$ & 21.10 & 21.8 & 22.30 & 21.00 & 19.50 & 22.10 & 19.70 & 22.00 & 28.80 & 16.8 & 23.10 & 20.70 & 23.40 & 18.80 \\
\hline SD & 19.94 & 19.65 & 20.85 & 18.81 & 19.10 & 19.50 & 19.14 & 19.49 & 25.21 & 14.71 & 24.05 & 16.90 & 21.09 & 17.05 \\
\hline \multicolumn{15}{|c|}{ Depression Score } \\
\hline $\mathrm{N}$ & 11.10 & 14.00 & 10.70 & 15.10 & 10.90 & 14.00 & 9.70 & 14.60 & 16.201 & 11.29 & 11.20 & 14.20 & 11.40 & 15.83 \\
\hline SD & 5.82 & 9.09 & 6.12 & 9.34 & 7.34 & 8.71 & 7.40 & 8.34 & 10.58 & 3.90 & 6.07 & 9.21 & 7.33 & 9.12 \\
\hline \multicolumn{15}{|c|}{ Motor Assessment Score } \\
\hline $\mathrm{N}$ & 33.00 & 33.40 & 34.60 & 32.20 & 32.30 & 35.40 & 35.20 & 31.60 & 32.90 & 36.00 & 33.60 & 33.10 & 34.10 & 31.90 \\
\hline SD & 9.31 & 11.26 & 10.90 & 10.44 & 9.23 & 11.60 & 9.05 & 11.43 & 10.03 & 12.14 & 10.87 & 10.63 & 10.75 & 10.52 \\
\hline \multicolumn{15}{|c|}{ Quality of Life Score } \\
\hline $\mathrm{N}$ & 189.90 & 177.80 & 186.1 & 0177.0 & 184,00 & 178.50 & 186.10 & 0193.20 & 177.90 & 192.00 & 184.20 & 179.90 & 186.90 & 0173.10 \\
\hline SD & 24.05 & 32.22 & 28.85 & 31.35 & 26.50 & 35.22 & 28.85 & 29.77 & 25.72 & 20.43 & 25.24 & 32.98 & 27.99 & 32.37 \\
\hline
\end{tabular}

LB - Libido CF- Coital Frequency ER- Erection EJ - Ejaculation VL- Vaginal Lubrication OR- Orgasm SS- Satisfaction with Sexual Life ND- No Dysfunction D- Dysfunction NNumber of Participants SD- Standard Deviation 
Table 5: Mann Whitney U Test for selected variables of participants with and without sexual dysfunction

\begin{tabular}{|c|c|c|c|c|c|c|c|}
\hline Variable & $\begin{array}{l}\text { LB } \\
\text { U* P-value }\end{array}$ & $\begin{array}{l}\text { CF } \\
U^{*} \text { P.value }\end{array}$ & $\begin{array}{l}\text { ER } \\
U^{*} \text { P-value }\end{array}$ & $\begin{array}{l}\text { Ej } \\
\text { U* P-value }\end{array}$ & $\begin{array}{l}\text { VL } \\
U^{*} \text { P.value }\end{array}$ & $\begin{array}{l}\text { OR } \\
U^{*} \text { P.value }\end{array}$ & $\begin{array}{l}\text { SS } \\
\text { U P}^{*} \text { P.value }\end{array}$ \\
\hline & 8.000 .482 & 00 & $267.000 .016^{* *}$ & 51 & 370 & 0.882 & 656. \\
\hline Strok & & & & & 321 & 692 & 0.395 \\
\hline & 336 & 065 & 30 & $010^{* *}$ & 25.000 .536 & 551.000 .283 & $454.500 .0211^{* *}$ \\
\hline & 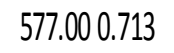 & 267 & & & 481 & 0.829 & 589.000 .322 \\
\hline tality of life Score & 491.500 .182 & 626.500 .361 & 390.000 .790 & $264.000 .033^{* *}$ & 24.000 .277 & 660.500 .991 & $494.500 .038 * *$ \\
\hline
\end{tabular}

LB- Libido CF- Coital Frequency ER- Erection EJ- Ejaculation

VL- Vaginal Lubrication OR- Orgasm SS-Satisfaction with Sexual Life U*= Mann Whitney U value

${ }^{*}$ statistically significant at $\mathrm{p}<0.05$

During data collection, many of the stroke survivors opined that it was the first time any healthcare professional was asking them questions relating to sexual function, an area of importance to them. They also expressed a desire for proper counseling on this aspect of their lives and suggested that sexual counseling be made a part of stroke rehabilitation.

\section{Discussion}

The mean age of stroke survivors in the present study is slightly lower than the mean age of those in previous stroke studies from Nigeria, which ranged from $60.6 \pm 12.4$ years to $62 \pm 13$ years ${ }^{15-17}$. There was a preponderance of male in the ratio $3.5: 1$ in this study. This is similar to the findings of previous studies from Nigeria and other parts of the world $^{6,7,15-17,18}$.

Almost all (95\%) the participants in this study reported at least one sexual dysfunction. This suggests that sexual dysfunction is common among Nigerian stroke survivors, as it is with stroke survivors from other parts of the world ${ }^{5-7}$. Dysfunction in coital frequency was the most frequently reported sexual dysfunction, followed by dysfunction in libido, orgasm, and erection. This is in line with the findings of Monga et al ${ }^{19}$ in which a $79 \%$ to $61 \%$ dysfunction in sexual activities was reported. The decline in libido, coital frequency, orgasm and satisfaction with sexual life reported by participants in this study are also similar to the findings of Korpelainen et $\mathrm{al}^{6}$, Kimura et $\mathrm{al}^{7}$ and Cheung ${ }^{20}$.

It is surprising that only $30(40 \%)$ of participants in this study reported dissatisfaction with sexual life. This is in spite of the fact that more participants reported sexual dysfunction in libido, coital frequency, erection, ejaculation and orgasm. In previous studies, higher proportions of participants (49-71\%) were reported to be dissatisfied with sexual life $\mathrm{f}^{6,7,20}$. In the Nigerian cultural context, ability to have children is perceived as a major determinant of satisfaction with sexual life. This cultural perception might have influenced participants' response to satisfaction with sexual life. Unfortunately, we did not survey how many of the participants had or did not have children and this is regarded as a limitation of this study.

The results of this study revealed that psychological factors (willingness to have sex, general attitude to sex and ability to express sexual feelings) have a negative influence on sexual function (libido, erection, coital frequency, ejaculation, orgasm and satisfaction with sexual life) post stroke. This agrees with previous reports ${ }^{5,6,18}$. The finding suggests that psychological factors play a crucial role in determining sexual function and satisfaction after stroke. Gender had no influence on the sexual function common to both gender (libido, orgasm, coital frequency and satisfaction with sexual life). This is similar to the findings of Buzzelli et $\mathrm{al}^{5}$ and Choi-Kwom and $\mathrm{Kim}^{21}$. Participants' sexual function was also not affected by the side of hemiparesis, however two psychosocial factors (fear of impotence and fear of another stroke episode) had no significant influence on sexual function. Boldrini et $\mathrm{al}^{22}$ reported that clinical features had no significant association with changes in sexual life.

Findings from this study showed that there was no significant difference between the motor assessment score of those with sexual dysfunction and those without sexual dysfunction in all the sexual 
activities assessed in this study. Buzzelli et al ${ }^{5}$ and Choi-Kwon et al ${ }^{21}$ also reported that motor disability has no effect on sexual activities post stroke. Kimura et $\mathrm{al}^{7}$ on the other hand, reported that physical disability is an important factor influencing post stroke sexual function.

The mean age of participants with erectile dysfunction (59.4 \pm 9.49 years) was found to be significantly higher than the mean age of those who

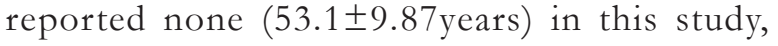
supporting the finding of Giaquinto et al ${ }^{18}$. This could be explained by the fact that sexual function appears to decline with age ${ }^{23}$. The depression scores of those with ejaculation dysfunction were significantly higher than the scores of those who reported no dysfunction in their sexual activities. Also, the depression score of participants who reported dissatisfaction with their sexual life was significantly higher than that of those who were satisfied with their sexual life. This supports the findings of Goddess et $\mathrm{al}^{24}$, Buzzelli et $\mathrm{al}^{5}$, Korpelainen et al ${ }^{25}$ and Kimura et al ${ }^{7}$ who reported that sexual dysfunction was closely associated with the degree of depression post stroke. On the other hand, Buzzelli et $\mathrm{al}^{5}$ found no significant association between depression and sexual variations. However, we observed that participants with sexual dysfunction in penile erection, ejaculation, and satisfaction with sexual life had significantly higher quality of life scores. It is not impossible that the cultural tendency of Nigerians not to arrogate negative things to themselves might have influenced the participants' response to items on the stroke specific quality of life scale.

\section{Conclusion}

The findings of this study suggest that decline in sexual function is common among Nigerian stroke survivors. Age, depression and psychological factors (attitude to sex, ability to express sexual feelings, unwillingness to have sex) have negative influence on sexual function of Nigerian stroke survivors. The implication of these findings is that assessment of sexual function and sexual counseling should be incorporated into the management of stroke survivors in Nigeria. This will necessitate training healthcare professionals involved in the care of stroke survivors in sex life counselling. Longitudinal studies will be necessary to ascertain the causes of sexual dysfunction among stroke survivors in Nigeria. However, this study has some limitations as regards the participants recruited. All were attending physiotherapy and so all were likely to have had mobility and/or upper limb disabilities. The participants were also married and/or lived with their spouse(s) or partner(s) leaving out single stroke survivors who masturbate and may use paid sexual service or have occassional sexual encounters. We suggest that these areas be looked into in future longitudinal studies.

\section{References}

1. Precipe M, Ferrefi C, Casini AR, Santini M, Giubi EF, Gulass F. Stroke disability and dementia. Stroke 1997; 28: 531-6.

2. Wolfe C.D.A. The impact of stroke. British Medical Bulletin 2000; 56: 275 - 286.

3. Humphries SV. A Study of hypertension in the Bahamas. South African Medical Journal 1957; 31:694 - 699.

4. Bray GP, DeFrank RS, Wolfe TL. Sexual functioning in stroke survivors. Archives of Physical Medicine and Rehabilitation 1981; 62: 286-8.

5. Buzzelli S, Di Francesco L, Giaquinto S, Nolfe G. Psychological and Medical Aspects of Sexuality Following Stroke. Sexuality and Disability. 1997; 15(4): 261-70.

6. Korpelainen JT, Nieminen P, Myllylä VV. Sexual functioning among stroke patients and their spouses. Stroke 1999; 30: 715-719.

7. Kimura M, Murata Y, Shimoda K, Robinson R.G. Sexual dysfunction following stroke. Comprehensive Psychiatry 2001; 2(3): 217-222.

8. Strauss D. Biopsychological issues in sexuality with the neurologically impaired patient. Sexuality and Disabiltiy. 1991; 9(1): 49-67.

9. Mclaughlin J, Cregan BA. Sexuality in stroke care: A neglected quality of life issue in stroke rehabilitation? A pilot study. Sexuality and Disability 2005; 23(4): 213-226.

10. Lamina S, Hanif SM, Darnley IKO, Ahmad RY. Effect of cerebrovascular accident on sexual function of male hemiplegic patients. Journal of Medicine and Rebabiliation. 2007; 1(1) 15-18.

11. Carr J, Shepherd R. Modified Motor Assessment Scale. Physical Therapy 1989; 69(9) 780.

12. Williams LS, Weinberger M, Harris LE, Clark DO, Biller J. Development of a stroke specific Quality of life Scale. Stroke 1999; 30: 1362-1369.

13. Beck AT, Rush AJ, Shaw BF, Emery D. (1979): Cognitive therapy of depression. New York.

14. Beaton DE, Bombardier C, Guilleman F, Ferraz MB: Guidelines for the process of Cross-

African Health Sciences Vol 13 Issue 3 September 2013 
Cultural adaptation of Self-Report Measures. Spine 2000; 25: 3156-3191

15. Amu E, Ogunrin O, Danesi M. Re- appraisal of risk factors for stroke in Nigerian AfricansA prospective case- control study. African Journal of Neurological Sciences. 2005; 24: 20-27.

16. Komolafe MA, Ogunlade O, Komolafe EO. Stroke Mortality in a Teaching Hospital in SouthWest of Nigeria. African Journal of Neurological sciences. 2006; 25: 75- 77.

17. Komolafe MA, Komolafe EO, Fatoye F, Adetiloye V, Asaleye C, Famurewa O. Profile of stroke in Nigerians: A prospective clinical study. African Journal of Neurological sciences. 2007; 26: 5-13.

18. Giaquinto S, Buzzelli S, Di Francesco L, Nolfe G. Evaluation of sexual changes after stroke. Journal of Clinical Psycbiatry. 2003; 64(3): 302-7.

19. Monga TN, Lawson JS, Inglis J. Sexual dysfunction in stroke patients. Archives of Physical Medicine and Rehabilitation. 1986; 67:19-22.
20. Cheung R.T. Sexual functioning in stroke patients with mild or no disability. CerebrovascularDiseases 2002;14:122-8.

21. Choi-Kwom S, Kim JS. Poststroke emotional incontinence and decreased sexual activity. Cerebrovascular Diseases 2002; 13: 31-37.

22. Boldrini P, Basaglia N, Calanca MC. Sexual changes in hemiparetic patients. Archives of Physical Medicine and Rehabilitation 1991; 72:202207.

23. [Hawton K. Sexual adjustment of men who have had strokes. Journal of Psychomatic Research 1984; 28(3): 243-249.

24. Goddess ED, Wagner NN, Silverman DR. Poststroke sexual activity in CVA patients. Medical Aspects of Human Sexuality 1979; 13: 16-30

25. Korpelainen JT, Kauhanen ML, Kemola H, Malinen U, Myllylä V V. Sexual dysfunction in stroke patients. Acta Neurology Scandinavia 1998; 98:400-405. 